\title{
KUINKA OPPINEITA TUOTETTIIN?
}

KLINGE, MATTI, KNAPAS, RAINER, LEIKOLA, ANTO, JA STRÖMBERG, JOHN: Kuninkaallinen Turun Akatemia 16401808, Helsingin yliopisto 1640 1990 ensimmäinen osa, Otava 1987.

Salli sinä, oi ikuinen Jumala, että tätä Turkulaista Akatemiaa ylistettäisiin koko maailmassa kuin Kreikkalaisten Ateenalaista; että se Teologisissa opinnoissa olisi Wittenbergin, Helmstedtin ja Rostockin veroinen. Ettei se Lainopin opinnoissa jäisi Marburgin, Altdorfin, Leizigin tai Jenan jälkeen. Että se Lääketieteellisessä tiedekunnassa vastaisi Padovaa, Freiburgia, Strasbourgia ja Pariisia. Että se Filosofian puhtaudessa kilpailisi kaikkien näiden ja muiden mainitsematta jääneiden kanssa. Että se isänmaassa kaikissa suhteissa ystävyydessä liittoutuisi Upsalan Akatemian kanssa! Michael Wexionius, 1640

Helsingin yliopiston historian ensimmäinen osa Kuninkaallinen Turun Akatemia 1640-1808 on perusteellinen yli 700-sivuinen katsaus akateemiseen elämään Suomessa Ruotsin vallan aikana. Kirjan tavoitteena on synteesi; se ei ole hakuteos tai käsikirja. Matti Klinge ja Anto Leikola pureutuvat aate- ja oppihistoriaan, lisäksi Klinge kirjoittaa yliopiston esihistoriasta ja perustamisesta, yliopistosta sosiaalisena ja taloudellisena instituutiona, ylioppilaista sekä opetuksesta ja opiskelusta. Rainer Knapas vastaa kirjan rakennushistoriallisesta osasta, ja John Strömberg osakuntalaitoksen ja ylioppilaiden sosiaalisen ja taloudellisen taustan selvittämisestä. Nimityksiin, akateemisiin kiistoihin ja oppiriitoihin, rituaaleihin ja symboleihin, yliopistollisiin sukuyhteisöihin, poliittisiin ja kansallisiin pyrkimyksiin sekä ylioppilaiden kontrolloimiseen monen muun yliopistolaitosta ohjaavan ja muovaavan tekijän ohella paneudutaan teoksessa seikkaperäisesti. Kirjoittajilla on myös hyvä kuriositeettien taju; sattumat ja hupaisat kum- majaisuudet elävöittävät tekstiä kuten myös ansiokkaan monipuolinen kuvitus.

\section{Hyöty ja valta}

Helsingin yliopiston historian ensimmäinen osa on paitsi kattava tutkimus ja mainioiden anekdoottien varasto myös perusteltu puheenvuoro Suomessa virinneeseen sivistyneistökeskusteluun. On kiinnostavaa arvioida, mitkä yliopistoelämää 1600 - ja 1700 -luvuilla leimanneista piirteistä ovat yhä tunnusomaisia tai ainakin tunnistettavissa suomalaisessa yliopistossa, sivistyneistössä ja kulttuurissa yleisesti.

Käytännöllis-hyödylliset ja valtapoliittiset tarpeet johtivat Kuninkaallisen Turun Akatemian perustamiseen 1640 ja määrittelivät sen toimintaa seuraavalla vuosisadalla. Kirkko tarvitsi entistä parempaa pappiskoulutusta, suurvalta Ruotsi uusia virkamiehiä ja yliopistot ja alemmat oppilaitokset opettajia. "Akatemia on julkinen koulu jossa korkeimman Virkamiehen (siis hallitsijan) antaman erioikeuden nojalla esitetään kaikkia sallittuja tieteitä (artes) ja jaetaan korkeimpia opin arvoja, jotta Jumalan kunniaa julistettaisiin ja Valtiossa lisääntyisi taitavien kansalaisten määrä", valtio-opin ja historian professori Michael Wexionius luonnehtii Kuninkaallisen Turun Akatemian ideologiaa 1644. Mistään kovin vapaasta akatemiasta voidaan tuskin puhua, vaikka yliopistolla oli alusta pitäen taloudellinen ja oikeudellinen autonomiansa. Yliopisto tuntuu olleen paljossa latinan pänttäämistä, teologiaa ja saarnataitojen harjoittelua, mutta samalla myös esimerkiksi filosofiaa, luonnontieteitä, runoutta ja kaunopuheisuutta luennoitiin.

Aatelisylioppilaiden koulutus oli asia erikseen. Se tähtäsi uusien kielten, ennen muuta ranskan, osaamiseen, ensimmäisen säädyn moraalin ja velvollisuuksien - ritarillisten hyveiden kuten "rohkeuden", "jalomielisyyden", "hurs- kauden ja oikeudenmukaisuuden" — opettelemiseen sekä käytännöllisiin taitoihin kuten miekkailuun, tanssiin ja musiikkiin. Aatelisnuorukaisilla ei tosin ollut tapana suorittaa tutkintoja, ja he mieluummin opiskelivat lyhyehköjä jaksoja eri kotimaisissa ja myös ulkomaisissa yliopistoissa. Virkavuodet olivat oppiarvoa painavampi meriitti.

Yliopisto ja valtiovalta kytkeytyivät tiiviisti toisiinsa Kuninkaallisessa Turun Akatemiassa, ja tämä perinne tuntuu myös jatkuvan. Akatemian ensimmäinen kansleri Per Brahe oli suurvaltaRuotsin johtavia poliitikkoja kuten monet myöhemmätkin kanslerit kuten Arvid Horn ja Carl Gustaf Tessin. Kuninkaan tai aristokratian toiveet tiedettiin hyvin akatemian konsistorissa. Muitakin mahdollisuuksia olisi ainakin periaatteessa ollut olemassa. Esimerkiksi monet saksalaiset yliopistot perustuivat ensisijaisesti kaupunkiporvariston tukeen.

350 vuotta yliopiston perustamisen jälkeen suomalaista yhteiskuntaa ohjataan vielä tai taas ensisijaisesti käytännöllistaloudellisista lähtökohdista. Juristit, ekonomistit, insinöörit ja sosiologit, Kuninkaallisen Turun Akatemian virkamies- ja pappiskoulutuksen perilliset ovat johdossa. Helsingin Sanomien intellektuellikyselyssä oppineiston tämä osa ei menestynyt erityisen hyvin, mutta sen tosiasiallista vaikutusvaltaa tuskin kiistetään. Sivistykseen itseisarvona Suomessa ei juuri panosteta, vaikka Snellmanin ja Cygnaeuksen fraaseja mielellään toistetaankin.

\section{Nurkkapatrioottien pelot}

1600-luvulla erityisesti puhdasoppisuuden kaudella Kuninkaallista Turun Akatemiaa vaivasi ulkomaalaisuuskammo. Vieraita aatteita pelättiin ja opettajakuntaan rekrytoitiin vain kotimaisia voimia, so. ruotsalaisia oppineita. Suomalaissyntyiset professorit olivat koko akatemian ajan vain pieni vähemmistö. Ulkomaalaisuuskam- 
mo ei liene harvinaista nykyisinkään suomalaisessa akateemisessa maailmassa. Opettajien rekrytointi on tuskin paljoa kansainvälisempää Helsingin yliopistossa kuin aikoinaan Turussa. Samanlainen nurkkakuntaisuus ei ollut ominaista kaikille suurvalta-Ruotsin yliopistoille. Liivinmaan ja Pommerin yliopistot Tartossa/Pärnussa ja Greifswaldissa olivat varsin kansainvälisiä, erityisesti saksalaisella opettajakunnalla - mikä on luonnollista - oli niissä vahva jalansija.

Yliopiston nurkkakuntaisuutta ilmentää myös tyytyminen ensisijaisesti tiedon vastaanottajaksi, kuten Kuninkaallisessa Turun Akatemiassa tapahtui. Pyrkimys tiedon kansainväliseksi tuottajaksi ja viejäksi ei ole liioin Helsingin yliopiston tai Suomen nykyisen yliopistomaailman leimallisia hyveitä. 1600-luvulla Turussa professoreita nimenomaisesti varoteltiin minkään uuden näkemyksen esittämisestä. 1700-luvulla hyväksyttiin edistyksen, hyödyn ja kokeellisen luonnontieteen ideat Baconin, Descartesin ja Wolffin muotoilemina, mutta siitä ei kuitenkaan seurannut yliopiston huimaa kansainvälistymistä vaan osin ruotsalaistuminen, kun yhä useammin luennoitiin ja väitökset laadittiin ruotsiksi latinan sijasta. Uusi innovatiivisempi ilmapiiri tuotti kuitenkin muutamia kansainvälisestikin huomattavia tiedemiehiä kuten tutkimusmatkailija ja talousopin professori Pehr Kalm, kemisti Johan Gadolin ja Pietarissa varsinaisen uransa luonut tähtitieteilijä Anders Laxell ja lisäksi monia valtakunnallisesti merkittäviä oppineita. Myös uushumanistinen reaktio tähän hyödyn ja tekniikan eetokseen oli voimakas: Henric Gabriel Porthan, Mathias Calonius ja Franz Michael Franzén.

\section{Tieteen klassikot}

Kuninkaallinen Turun Akatemia 1640-1808 tarjoaa monia kiehtovia aatehistoriallisia välähdyksiä. On sääli ja häpeä, että vain pieni osa aivan keskeisimmistäkään Turussa julkaistuista tieteellisistä teoksista on saatavina nykyaikaisina käypinä käännöksinä tai editioina. Yliopistokirjallisuuden klassikoiden huolto on Suomessa skandaalimaisella tolalla, ja sama koskee muutakin vanhempaa intellektuaalista kirjallisuutta. Anders Chydeniuksen kasvot ilmestyivät pari vuotta sitten ilahduttavasti tuhannen markan seteliin, mutta pätevää käännöstä hänen teoksistaan ei tunnu olevan varaa tai kiinnostusta tuottaa. Viime vuonna juhlittiin kirjan 500-vuotista taivalta Suomessa, mutta klassikoiden saatavuuden suhteen edistyttiin tuskin askeltakaan lukuunottamatta Missale Aboensen rituaalista korulaitosta, joka latinankielisenä jäi sisällöllisesti useimmille lukijoille lähes täysin vieraaksi.

Tänä vuonna, kun vietetään Ranskan vallankumouksen 200vuotisjuhlallisuuksia, olisi erinomainen ajankohta julkaista Suomen keskeisintä valistuskirjallisuutta käsittävä kokoelma, jossa esimerkiksi Johan Browallius, Petter Forsskåhl, Pehr Kalm, Anders Chydenius, Pehr Adrian Gadd, Jacob Gadolin, Sigfried Porthan, Henric Gabriel Porthan, Mathias Calonius ja Franz Michel Franzén olisivat edustettuina. Usein väite-

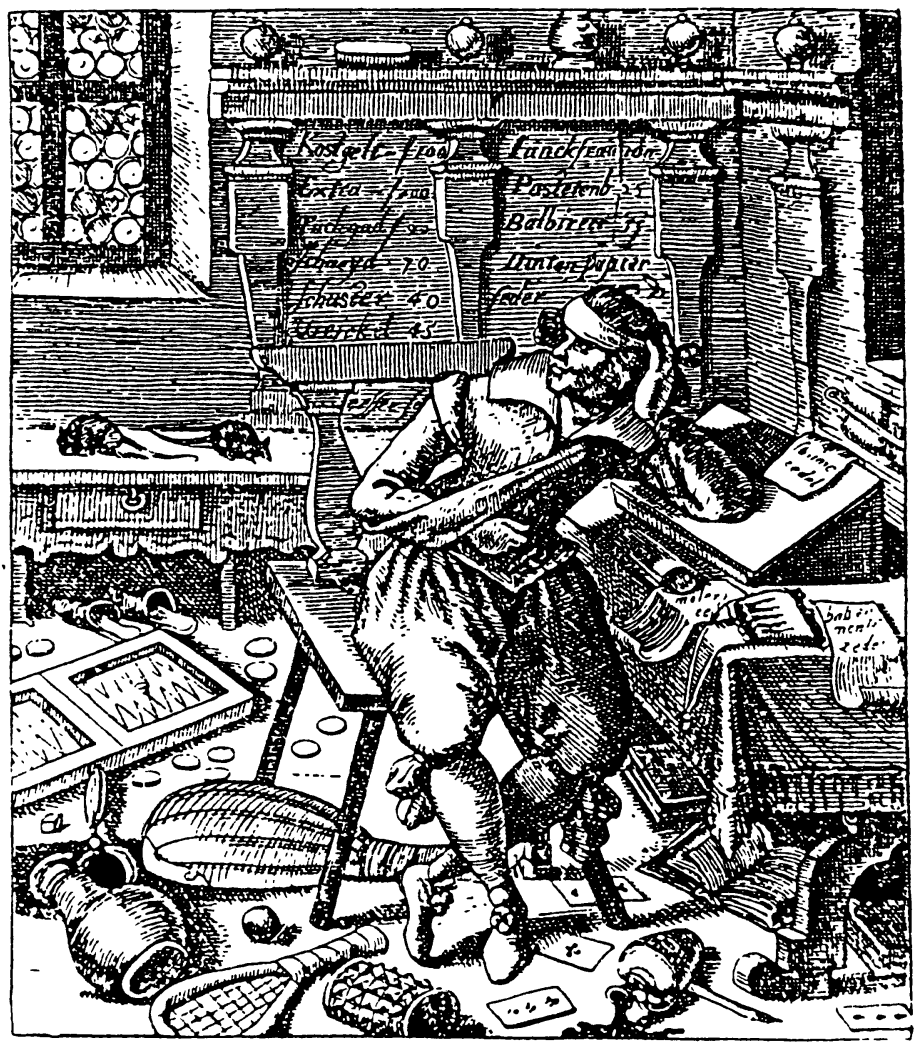

Huvituksiin ja turhuuksiin taipuvainen ylioppilas 1600-luvulta viinikannuineen ja peleineen. Mustepullokin on kaatunut! 


\section{SUOMI MIEHITTI — HISTORIA VAIKENEE}

tään, ettei Suomessa ole valistuskirjallisuutta, mutta se on erehdys. Valistuskirjallisuus kirjoitettiin Suomessa latinaksi ja ruotsiksi ja sillä on oma erityislaatunsa.

Suomalaista kirjallisuutta ja samalla kansallista itseymmärrystä kaventaa tietämättömyys omista historiallisista kerrostumista, siksikin intellektuaalisen kirjallisuutemme klassikoiden saattaminen nykylukijoiden ulottuville olisi välttämätöntä. Parhaiten se ehkä toteutuisi perustamalla Suomen tieteen klassikoiden kirjasarja.

\section{Kimmo Sarje}

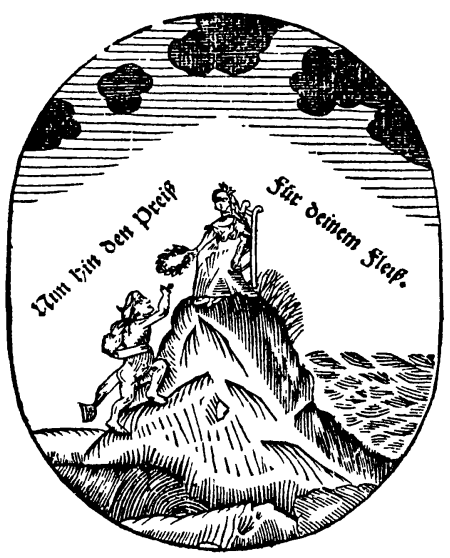

Viisauden jumalatar palkitsee Parnassos-vuorelle kipuavan ylioppilaan seppeleellä. Maisteri Tammelinin onnittelurunon kuvitusta vuodelta 1694.
SEPPÄLÄ, HELGE: Suomi miehittäjänä 1941-1944. SN-kirjat, 1989.

Ilmestyessään viime keväänä Helge Seppälän teos aiheutti kahdesta syystä pientä hälinää. Ensinnäkin sen aiheesta, Suomen sota-ajan miehitystoiminnasta NeuvostoKarjalassa on tähän asti oltu melko vaiteliaita. Hävitystä sodasta on tahdottu muistaa vain voitettuja taisteluita. Lisäpotkua Seppälä sai, kun hänen vakituinen kustantajansa ei ottanut teosta kustannusohjelmaansa, vaan sen julkaisi SN-kirjat, jonka kustannuspolitiikka yleensä keskittyy enemmän Suomen ja Neuvostoliiton ystävyyden kuin vihollisuuksien esittelyyn.

Toiseksi Seppälän väitettiin plagioineen muiden tutkimuksia, ennen kaikkea Antti Laineen teosta Suur-Suomen kahdet kasvot. ItäKarjalan siviiliväestön asema suomalaisessa miehityshallinnossa 1941-1944 (1982). En ole voinut verrata, minkä verran Seppälä on velkaa Laineelle ja muille ammattihistorioitsijoille. Ainakin hän viittaa Laineeseen pitkiin matkaa ja mainitsee tämän jo esipuheensa ensi riveillä tunnustaen yllä mainitun tutkimuksen olleen oman työnsä liikkeelle sysääjänä selvittämään, miksi Suomen sodanaikaisen miehitystoiminnan osalta on podettu pitkällistä muistinmenetystä ja tietoisesti valehdeltu. Seppälä on perehtynyt huolellisesti Itä-Karjalan sotilashallintoesikunnan jälkeenjääneisiin papereihin ja muuhun sota-arkiston dokumenttimateriaaliin. Muita keskeisiä lähderyhmiä ovat kotimaisen tutkimuskirjallisuuden ohella venäjänkielinen historiantutkimus ja muistelmat sekä Petroskoissa suoritetut miehityksen kokeneiden henkilöiden haastattelut.

Seppälä käyttää toistuvasti totuudenmukaisuuden käsitettä, jo esipuheessa: "Tämä kirja [Seppälän edellinen teos Suomi hyökkääjänä (1984)] sai totuudenmukaisuudestaan huolimatta eräissä piireissä poliittisen merkityksen ja ankarat arvostelut, /_l' (s. 7).
Varmaan sai, mutta on kysyttävä, voiko historiantutkimuksessa kuten muussakaan humaniorassa olla ehdotonta totuutta.

Seppälä lähtee liikkeelle yhdestä Mannerheimin retorisesta loistonäytteestä, kuuluisasta toisesta "miekantuppikäskystä" 10.7.1941. Seppälä pitää sitä marsalkan virheenä, huitaisuna tuntemattomaan tulevaisuuteen, josta saatiin maksaa sodan päätyttyä; toisaalta se oli "vallankaappaus", joka heikensi presidentti Rytin asemaa. Tämä ja monet muut detaljit osoittavat Suomen valmistautuneen hyökkäyssotaan Saksan rinnalla ja liittämään historiallisesti sille kuulumattoman Itä-Karjalan itseensä (Jalmari Jaakkolan Rytille tekemän muistion mukaan Venäjältä oli vaadittava jopa Kuolaa!). Näin Suomi oli ottamassa paikkaansa akselin "Uudessa Euroopassa" ja laajentumassa Suur-Suomeksi AKS:n hahmotteleman ohjelman mukaan.

Sen mukaisesti ryhdyttiin kesällä ja syksyllä 1941 toteuttamaan vallatun karjalaisalueen miehityshallintoa ja järjestelemään oloja uudelleen. Suomi ei tyytynyt vain eliminoimaan aseellista ja aseetonta vastarintaa, vaan pyrki puhdistamaan väestön vieraista aineksista, jotta se voitaisiin lukea Suomen kansaan. Ihmiset jaettiin kahteen kastiin, kansallisiin eli suomenheimoisiin (pääasiassa karjalaisia) ja epäkansallisiin, joista suurin ryhmä olivat venäläiset, yleensäkin Neuvosto-Karjalan enemmistökansallisuus. Tämä rotuerottelu näkyi työpalkoissa, elintarvikejakelussa, terveydenhoidossa, avioluvissa jne. Suomalainen apartheid näkyi myös liikkumisvapauden rajoituksissa: kansallisilla oli sininen ja venäläisillä punainen kulkulupa; jälkimmäisille myönnettiin muuttolupia hyvin vähän.

Pääasiassa epäkansallisia suljettiin Mannerheimin käskystä suurin joukoin keskitysleireihin; vuonna 1942 niissä oli 24 000, seuraavana vuonna 15000 ihmistä, enimmillään $27 \%$ miehitetyn alueen väestöstä. Seppälä korostaa, että näitä 